Highlighted article

\title{
Examination of the uncertainty in contaminant fate and transport modeling: A case study in the Venice Lagoon
}

\author{
J. Sommerfreund ${ }^{a}$, G.B. Arhonditsis ${ }^{\text {b,c,* }}$, M.L. Diamond ${ }^{\mathrm{a}, \mathrm{c}}$, M. Frignani ${ }^{\mathrm{d}}$, G. Capodaglio ${ }^{\mathrm{e}}$, M. Gerino ${ }^{\mathrm{f}}$, \\ L. Bellucci ${ }^{\mathrm{d}}$, S. Giuliani ${ }^{\mathrm{d}}$, C. Mugnai ${ }^{\mathrm{d}}$ \\ a Department of Chemical Engineering and Applied Chemistry, University of Toronto, Toronto, ON, Canada \\ ${ }^{\mathrm{b}}$ Department of Physical and Environmental Sciences, University of Toronto, Toronto, ON, Canada

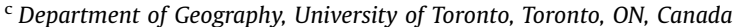 \\ ${ }^{\mathrm{d}}$ National Research Council, Institute of Marine Sciences, Bologna, Italy \\ e Department of Environmental Sciences, University of Venice, Venice, Italy \\ ${ }^{\mathrm{f}}$ Laboratory of Ecology of Hydrosystems, University of Toulouse, Toulouse, France
}

\section{A R T I C L E I N F O}

\section{Article history:}

Received 28 January 2009

Received in revised form

2 May 2009

Accepted 4 May 2009

Available online 2 June 2009

Keywords:

Contaminant fate and transport modeling

Venice lagoon

Uncertainty analysis

Multimedia modeling

Environmental management

\begin{abstract}
A B S T R A C T
A Monte Carlo analysis is used to quantify environmental parametric uncertainty in a multi-segment, multi-chemical model of the Venice Lagoon. Scientific knowledge, expert judgment and observational data are used to formulate prior probability distributions that characterize the uncertainty pertaining to 43 environmental system parameters. The propagation of this uncertainty through the model is then assessed by a comparative analysis of the moments (central tendency, dispersion) of the model output distributions. We also apply principal component analysis in combination with correlation analysis to identify the most influential parameters, thereby gaining mechanistic insights into the ecosystem functioning. We found that modeled concentrations of $\mathrm{Cu}, \mathrm{Pb}, \mathrm{OCDD} / \mathrm{F}$ and PCB- 180 varied by up to an order of magnitude, exhibiting both contaminant- and site-specific variability. These distributions generally overlapped with the measured concentration ranges. We also found that the uncertainty of the contaminant concentrations in the Venice Lagoon was characterized by two modes of spatial variability, mainly driven by the local hydrodynamic regime, which separate the northern and central parts of the lagoon and the more isolated southern basin. While spatial contaminant gradients in the lagoon were primarily shaped by hydrology, our analysis also shows that the interplay amongst the inplace historical pollution in the central lagoon, the local suspended sediment concentrations and the sediment burial rates exerts significant control on the variability of the contaminant concentrations. We conclude that the probabilistic analysis presented herein is valuable for quantifying uncertainty and probing its cause in over-parameterized models, while some of our results can be used to dictate where additional data collection efforts should focus on and the directions that future model refinement should follow.
\end{abstract}

(c) 2009 Elsevier Inc. All rights reserved.

\section{Introduction}

Contaminant mass balance fate and transport models are useful heuristic tools extensively used to gain insight into system dynamics and to estimate contaminant concentrations and loadings (Diamond et al., 1994, 2005; Wania and Mackay, 1999). These models are simplifications of reality and as such are inherently uncertain. Model uncertainty derives from both structural and parametric uncertainty (Spear, 1997). Structural uncertainty not only reflects the inability to capture all the significant processes underlying system behavior, but also the

\footnotetext{
* Corresponding author at: Department of Physical and Environmental Sciences, University of Toronto, Toronto, ON, Canada. Fax: +14162877279.

E-mail address: georgea@utsc.utoronto.ca (G.B. Arhonditsis).
}

inability to express them in an unequivocal manner in the model. For example, even if we develop a model of optimal complexity that comprises all the essential components of the real system, we usually realize that most ecological and physical processes can be described mathematically by a variety of relationships that entail different assumptions and levels of complexity (Arhonditsis et al., 2006). On the other hand, parametric uncertainty refers to the inability to accurately specify the values of the parameters of the mathematical structure used to represent the system. Parametric uncertainty stems from the analytical errors, the imprecision of measurements as well as spatio-temporal parameter variability (McKone, 1996).

The latter source of uncertainty is of particular importance in fate and transport modeling in which the relative effects of individual parameters on model predictions are not well understood and can be contaminant-specific (Matthies et al., 2004). 
The parameters represent physico-chemical properties of substances (e.g., partition coefficients), environmental system variables (e.g., sediment deposition rates) and contaminant emission/ loading estimates (e.g., tributary loadings). Many of the input parameters are difficult to measure (e.g., chemical degradation rates), others exhibit significant spatiotemporal variability (e.g., concentration of total suspended sediment), and existing system information cannot unambiguously support their characterization (Arhonditsis et al., 2006). For example, fate and transport models of aquatic systems require an estimate of the sediment resuspension flux which is characterized by considerable seasonal and spatial variation (Sfriso et al., 2005a). Thus, a single value assigned to this parameter is a clear over-simplification that essentially represents an "effective" (spatially/temporally averaged) value. This problem of parameter uncertainty can be partly overcome by increasing the spatial and/or temporal model resolution, but the greater data requirements of the refined grids/increased time steps are rarely met while the models become excessively complex, which introduces further error and uncertainty. Therefore, despite its inability to fully accommodate the spatial and temporal variability of model parameters, the adoption of a coarser resolution in space and time is a pragmatic solution that reflects the inevitable tradeoffs between model articulation and knowledge gained (Costanza and Sklar, 1985).

Because contaminant fate and transport models are often used to inform environmental management decisions, it is important to clearly communicate the uncertainty underlying model outcomes. Decision makers need to consider both the mean predictions and the associated confidence intervals (Reckhow, 1994). The problem of uncertainty of mathematical models has received considerable attention in the field of water resources management and several studies have rigorously addressed issues pertaining to structural and parametric errors (Spear, 1997; Omlin and Reichert, 1999; Pappenberger and Beven, 2006). Nonetheless, a recent metaanalysis showed that most of the aquatic mechanistic biogeochemical models published over the last decade did not adequately assess prediction error; modelers are still disinclined to embrace uncertainty analysis techniques and to assess the reliability of the critical planning information generated by the models (Arhonditsis and Brett, 2004). This reluctance is pronounced in contaminant fate and transport modeling, although efforts to systematically assess the underlying uncertainty can been found in the literature (e.g., McKone and Ryan, 1989; McKone, 1994; Kuhne et al., 1997; Liu et al., 1999; Webster et al., 2004). Recognizing the existing methodological gap, Cowan et al. (1994) and then Wania and Mackay (1999) underscored the importance of developing simple tools for evaluating uncertainty in multi-chemical, multi-media models.

In this paper, we present a Monte Carlo analysis for quantifying environmental parameter uncertainty in a multi-segment, contaminant fate and transport model based on the fugacity/ aquivalence approach of Diamond et al. (1992) and Mackay (2001). We analyze the fate of two metals $(\mathrm{Cu}$ and $\mathrm{Pb})$ and three POPs (octachloro dibenzo-p-dioxin (OCDD), octachloro dibenzofuran (OCDF) and PCB-180) in the Venice Lagoon. Sommerfreund et al. (2009) provide full details of the model, its parameterization and results from a deterministic analysis. In this study, scientific knowledge, expert judgment and observational data are used to formulate prior probability distributions and to characterize the uncertainty pertaining to 43 environmental system parameters. Uncertainty propagation through the model is then assessed by a comparative analysis of the moments (central tendency, dispersion) of the model output distributions. Finally, we apply principal component analysis (PCA) in combination with correlation analysis to identify the most influential parameters and to gain insight into the system dynamics, at least as depicted in our model.

\section{Material and methods}

\subsection{Study system}

The Venice Lagoon (Fig. 1) is composed of three basins (north, central and southern) defined by three inlets to the Adriatic Sea (Lido, Malamocco and Chioggia). It is a network of channels and mud flats with few principal deep channels $\left(>15 \mathrm{~m}\right.$ ), covering a $550 \mathrm{~km}^{2}$ area with a mean depth of $1.1 \mathrm{~m}$ (Solidoro et al., 2004a). The amplitude of the prevailing diurnal tidal flow can be greater than $1 \mathrm{~m}$ (Umgiesser et al., 2004). The Venice Lagoon receives inflows from 12 major tributaries resulting in water quality (dissolved oxygen, organic matter, suspended sediment) and physical parameter (e.g., salinity) gradients from the main land to the Adriatic Sea (Solidoro et al., 2004a). The lagoon is turbid, with net sediment loss from the central basin as a result of resuspension promoted by anthropogenic activities, e.g., the introduction of manila clams, clam fishing (Sfriso et al., 2005b), historic river diversion (Degetto and Cantaluppi, 2004) and a high frequency of boating and mechanical dredging (Pranovi et al., 2004).

Sediment profiles suggest that peak contaminant loadings to the Venice Lagoon from the industrial area of Porto Marghera occurred from 1950s to 1980s (e.g., Frignani et al., 2001; Frignani et al., 2005). Present loadings mainly originate from the industrial area of Porto Marghera (Bellucci et al., 2002; Carrer and Leardi, 2006), export from the watershed via tributaries (Collavini et al., 2005), remobilization of contaminated sediments (Sommerfreund et al., 2009), direct atmospheric deposition to the lagoon (Gambaro et al., 2004; Guerzoni et al., 2004) and discharges from municipalities. Our study focuses on the contaminants with the most complete data sets; namely, OCDD, OCDF, PCB-180, Cu and Pb.

\subsection{The Venice Lagoon model}

Full details of the Venice Lagoon model are presented by Sommerfreund et al. (2009). The model is based on the fugacity/aquivalence approach of Mackay (2001), Diamond et al. (1992) and Bhavsar et al. (2004), to estimate the concentrations of single species POPs and multi-species metals. To accommodate the spatial variability of the system, a ten-box model was constructed in which each segment consists of three compartments, i.e., water, upper and lower sediment (Fig. 1). Model segmentation follows that of Solidoro et al.'s (2004b) twodimensional hydrodynamic model used to reproduce the spatial variability of the lagoon water quality. We have adopted their reference scenario which reflects steady-state hydrologic circulation patterns in the system, assuming no wind, mean annual tributary flows and an idealized sinusoidal M2 tide level at the inlets (Solidoro et al., 2004b)

The model considers both depositional (segments $1-5,9,10$ ) and erosive (segments 6-8) environments. In depositional environments, net sediment accumulation occurs and water exchanges mass with the upper sediment compartments via particle-bound deposition/resuspension and bidirectional diffusion. The exchanges of mass between upper and lower sediment layers occur by biological/physical mixing and bidirectional diffusion. Contaminants are

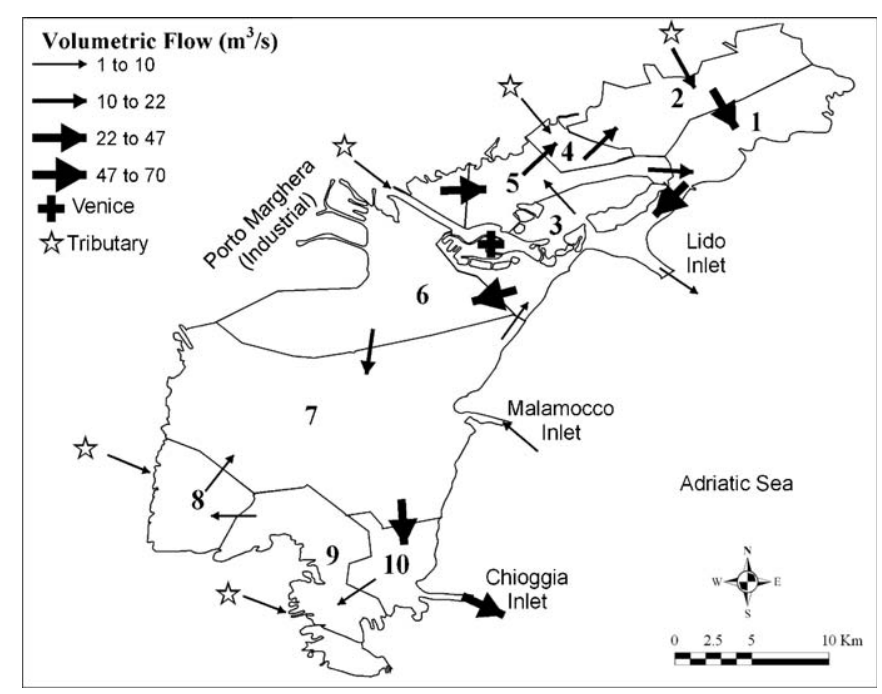

Fig. 1. The ten segments and the hydrologic circulation patterns considered by the Venice Lagoon model (Solidoro et al., 2004a). The industrial area of Porto Marghera neighbors segment 6 . Segments $6-8$ were modeled as erosive areas, while erosion of in-place pollution occurs in segment 6 . The northern, central and southern basins are represented by segments $1-5$, segments $6-8$ and segments 9 and 10 , respectively. 
removed from the lower sediment layer via burial. In the erosive environments, a sediment introduction term and an upward transfer term are defined as the addition of sediment from below the lower sediment layer and from there to the upper sediment layer, respectively. These parameters are the opposite of the burial pathway and maintain a constant volume in the sediment compartments. Using a pseudo-steady-state formulation (Diamond, 1995) in which we specify the fugacity/aquivalence of the lower sediment layer, the model explicitly considers the erosion-driven remobilization of contaminants accumulated in the sediments of segment 6 , neighboring the industrial area.

A mass balance equation is constructed for each compartment in each segment to represent the chemical mass change in water, upper and lower sediment with time. Steady-state solutions are used to estimate the fugacity/aquivalence of water, upper and lower sediment of each segment (excluding lower sediment of segment 6 , which is assigned a concentration as part of the pseudo-steady-state formulation).

\subsection{Contaminants_external loadings}

As mentioned above, OCDD, OCDF, PCB-180, Cu and Pb were selected based on their abundance in the lagoon, toxicity and completeness of loading data. Our model considers loadings to the lagoon from tributaries, discharges from the industrial area of Porto Marghera, contributions from historically contaminated sediments and atmospheric deposition. Each contaminant source is briefly described below. Sommerfreund et al. (2009) explain the derivation of each loading term. Tributary inputs of dissolved and particulate phases of $\mathrm{Pb}, \mathrm{Cu}$ and PCB-180 were obtained from Collavini et al. (2005) who reported measured concentrations at outlets of 11 major tributaries in 1999. Since only four tributaries were measured for OCDD/F, we estimated loadings in unmeasured tributaries by assigning concentrations from the four measured tributaries to the unmeasured tributaries in the same subwatershed. Industrial loadings were obtained from MAV-SAMA (2004) and Ferrari (personal communication) who calculated loadings as the difference between water entering and exiting a facility annually. Data were used from 2001 with the exception of OCDF for which we used values from 2002 Bulk atmospheric deposition of PCBs and PCDD/Fs were modeled using gas-phase measurements at segments 3 and 6 every 15 days from March 2002 to June 2003 when the wind speed exceeded $1 \mathrm{~m} \mathrm{~s}^{-1}$ (Gambaro et al., 2004; Manodori et al., 2006). Metal deposition was calculated from measured $\mathrm{PM}_{10}$, and thus may underestimate total deposition. Atmospheric stack emissions were not explicitly included. Loading of historically contaminated sediment from the area adjacent to the industrial district (segment 6), reintroduced into the system through the transport of sediment (erosion driven) from the lower to upper sediment (Upward 6), was estimated using a pseudo-steady-state approach (Diamond, 1995). The fugacity/aquivalence of the lower sediment was calculated from the geometric mean of the measured lower sediment concentrations from three sediment cores (Frignani et al., 2001, 2004).

\subsection{Parameterization}

We selected a subset of environmental parameters (Table 1) from Sommerfreund et al. (2009) who found that particle dynamics largely controls the fate of contaminants studied in the lagoon. The selected parameters were: total suspended sediment (TSS), sediment trap flux (ST), burial (Bur), mixing between upper and lower sediment layers (Mix), and erosion-driven addition of sediment from below the lower sediment (SedIntro-segments 6 to 8 ) and from the lower to the upper sediment (Upward-segments 6 to 8).

To characterize the uncertainty pertaining to environmental parameters (prior parameter distributions) we identified minimum and maximum values for each parameter from available measurement data and assigned lognormal distributions parameterized such that a fixed percentage of their values lay within the identified ranges (e.g., Steinberg et al., 1997). For example, Sfriso et al. (2005b) presented 3-yr sediment trap data in segments 6 and 7 that were collected from 4 sampling sites from which we derived a plausible, lognormally distributed range of resuspension rates. The probability of observing values out of the specified range was assumed to be only $1 \%$ reflecting high level of confidence in the information from the system. For some parameters, sufficient data were not available for constructing prior distributions for each segment. Consequently, all measurement data were compiled to create one distribution for the lagoon that was sampled independently for each segment (Table 1). Parameter distributions were sampled using Monte Carlo sampling with Crystal Ball ${ }^{\mathrm{TM}}$.

We did not consider the uncertainty of the physico-chemical contaminant properties because our focus was on model inputs that are common across contaminants, e.g., we did not consider degradation half lives since metals are nondegradable. Physico-chemical properties of contaminants and their literature sources are presented in Table 2 while Table 3 presents the segment dimensions and the associated parameter values used for the Venice Lagoon model (Solidoro et al. 2004a). To further reduce the number of the sampled model inputs and also

Table 1

Uncertainty analysis of the Venice Lagoon model: definitions and summary statistics of the model parameters examined.

\begin{tabular}{|c|c|c|c|}
\hline Parameter and units & Definition & Geometric mean & Multiplicative variance \\
\hline $\mathrm{ST} 1\left(\mathrm{~g} / \mathrm{m}^{2} \mathrm{~d}\right)^{\mathrm{a}}$ & $\begin{array}{l}\text { Particle exchange (sum of deposition and resuspension) between the water } \\
\text { column and the sediment }\end{array}$ & 142.1 & 2.7 \\
\hline ST2 $\left(g / m^{2} d\right)^{a}$ & & 142.1 & 2.7 \\
\hline ST3 $\left(g / m^{2} d\right)^{a}$ & & 934.0 & 2.4 \\
\hline ST $4\left(\mathrm{~g} / \mathrm{m}^{2} \mathrm{~d}\right)^{\mathrm{a}}$ & & 497.5 & 2.1 \\
\hline ST5 $\left(g / m^{2} d\right)^{a}$ & & 1213.6 & 1.9 \\
\hline ST6 $\left(\mathrm{g} / \mathrm{m}^{2} \mathrm{~d}\right)^{\mathrm{a}}$ & & 718.2 & 2.1 \\
\hline ST7 $\left(g / m^{2} d\right)^{a}$ & & 101.1 & 3.0 \\
\hline ST8 $\left(g / m^{2} d\right)^{a}$ & & 101.1 & 3.0 \\
\hline ST9 $\left(\mathrm{g} / \mathrm{m}^{2} \mathrm{~d}\right)^{\mathrm{a}}$ & & 746.0 & 1.8 \\
\hline $\operatorname{ST} 10\left(g / m^{2} d\right)^{a}$ & & 746.0 & 1.8 \\
\hline TSS $1\left(\mathrm{~g} / \mathrm{m}^{3}\right)^{\mathrm{b}}$ & Total suspended sediment in the water column & 15.9 & 1.9 \\
\hline TSS $2\left(\mathrm{~g} / \mathrm{m}^{3}\right)^{\mathrm{b}}$ & & 15.4 & 1.9 \\
\hline TSS $3\left(\mathrm{~g} / \mathrm{m}^{3}\right)^{\mathrm{b}}$ & & 14.1 & 1.9 \\
\hline TSS $4\left(\mathrm{~g} / \mathrm{m}^{3}\right)^{\mathrm{b}}$ & & 22.5 & 1.9 \\
\hline TSS $5\left(\mathrm{~g} / \mathrm{m}^{3}\right)^{\mathrm{b}}$ & & 22.5 & 1.9 \\
\hline TSS $6\left(\mathrm{~g} / \mathrm{m}^{3}\right)^{\mathrm{b}}$ & & 22.2 & 1.9 \\
\hline TSS $7\left(\mathrm{~g} / \mathrm{m}^{3}\right)^{\mathrm{b}}$ & & 11.3 & 1.9 \\
\hline TSS $8\left(\mathrm{~g} / \mathrm{m}^{3}\right)^{\mathrm{b}}$ & & 17.0 & 1.9 \\
\hline TSS $9\left(\mathrm{~g} / \mathrm{m}^{3}\right)^{\mathrm{b}}$ & & 16.2 & 1.9 \\
\hline TSS $10\left(\mathrm{~g} / \mathrm{m}^{3}\right)^{\mathrm{b}}$ & & 10.4 & 1.9 \\
\hline $\operatorname{Bur}\left(g / m^{2} d\right)^{b, f}$ & Sediment accumulation (from $\mathrm{Pb}^{210}$ data) & 3.7 & 1.2 \\
\hline SedIntro $\left(g / m^{2} d\right)^{c, f}$ & $\begin{array}{l}\text { Flux of sediment particles transferred from below the lower sediment into the } \\
\text { lower sediment }\end{array}$ & 10.7 & 2.3 \\
\hline Upward $\left(g / m^{2} d\right)^{c, f}$ & Flux of sediment particles transferred from the lower into the upper sediment & & \\
\hline $\operatorname{Mix}\left(g / m^{2} d\right)^{d, e, f}$ & $\begin{array}{l}\text { Flux of sediment particles between sediment layers caused by physical and } \\
\text { biological mixing }\end{array}$ & 0.2 & 1.5 \\
\hline
\end{tabular}

a Sfriso et al. (2005a, b).

b MAV-SAMA (2004).

c Adriano et al. (2005)

d Diamond (1995).

e Bhavsar et al. (2004).

${ }^{\mathrm{f}}$ Generated one distribution, sampled individually for each segment. 
Table 2

Physical and chemical properties of organic contaminants.

\begin{tabular}{|c|c|c|c|c|c|c|c|}
\hline $\begin{array}{l}\text { Chemical } \\
\text { name }\end{array}$ & $\begin{array}{l}\text { Molecular weight } \\
\left(\mathrm{g} \mathrm{mol}^{-1}\right)\end{array}$ & $\begin{array}{l}\text { Melting Point }{ }^{\mathrm{a}} \\
\left({ }^{\circ} \mathrm{C}\right)\end{array}$ & $\begin{array}{l}\text { Solubility }^{\mathrm{a}} \\
\left(\mathrm{mol} \mathrm{m}^{-3}\right)\end{array}$ & $\begin{array}{l}\mathrm{HLC}^{\mathrm{a}} \\
\left(\mathrm{Pa} \mathrm{m}^{3} \mathrm{~mol}^{-1}\right)\end{array}$ & $\log K_{\text {ow }}{ }^{a}$ & $\begin{array}{l}\text { Half-life water }{ }^{b} \\
\text { (h) }\end{array}$ & $\begin{array}{l}\text { Half-life } \\
\text { sediment }^{\mathrm{b}}(\mathrm{h})\end{array}$ \\
\hline OCDD & 460 & 322 & $1.608 \times 10^{-7}$ & 0.680 & 8.2 & 79,000 & $1,300,000$ \\
\hline OCDF & 443 & 258 & $2.614 \times 10^{-6}$ & 0.190 & 8.0 & 192,000 & 250,000 \\
\hline РCB-180 & 395 & 110 & $9.309 \times 10^{-7}$ & 1.013 & 7.9 & 240,000 & 330,000 \\
\hline
\end{tabular}

a Mackay (2001).

b Sinkkonen and Paasivirta (2000).

to avoid confounding effects on the environmental parameters, the impact of the uncertainty pertaining to the loading/emission estimates to overall model uncertainty was not examined. Finally, it should be noted that our model does not consider loadings to the lagoon from the City of Venice, and shipping and boat emissions due to lack of data. The absence of full loading data adds to model uncertainty.

\subsection{Data analysis}

The uncertainty underlying model predictions for the water and upper sediment $(0-3 \mathrm{~cm})$ concentrations was quantified using both the inter-quartile range (difference between the 75 th and 25 th percentiles) and the logarithm of the quotient of the 90th and 10th percentiles (range of distribution or RoD) of the respective distributions. We also applied principal component analysis (PCA) to analyze the spatial variability in the Venice Lagoon (Jassby, 1999). The rationale behind this application of PCA is that each segment of the lagoon may be regulated by different processes and may therefore behave independently of each other and impede the identification of the most significant causal factors/influential parameters. Thus, PCA was used to unravel the number of independent modes of spatial variability and the segments in which they were most important (factor loadings) along with their relative strength from one Monte Carlo run to another (factor scores). A data matrix of 10 columns (segments) and 45,000 rows (Monte Carlo runs) was formed for each contaminant for water and upper sediment concentrations. We retained factors with eigenvalues greater than 1 (Kaiser criterion) which essentially means that all the principal components (PCs) considered in this analysis extracted variability at least as much as the equivalent of one original variable (Legendre and Legendre, 1998). We then computed the correlation matrix between PCA factor scores and the model parameters to identify the most significant causal relationships in each mode of spatial variability.

\section{Results and discussion}

\subsection{Model performance}

Using Monte Carlo sampling, we generated 45,000 random sets from the prior probability distributions of 43 environmental parameters which then provided the input for our contaminant fate and transport model. To evaluate the model, the predicted contaminant medians and inter-quartile ranges were compared with single measured concentrations and (where available) measurement ranges. For soluble (dissolved and colloidal) phase $\mathrm{Pb}$ and $\mathrm{Cu}$ concentrations, predicted medians and inter-quartile ranges were compared with the corresponding median values and inter-quartile ranges from 3-year averages of monthly measured concentrations at 27 stations that cover the entire lagoon (with the exception of segment 4). Measurements were not available for water column PCB-180, OCDD and OCDF concentrations. For the upper sediment, estimated inter-quartile ranges were compared against measurements obtained from one core in each of segments 2, 4 and 10 for all contaminants; an additional single core in segment 7 for Pb, Cu, PCB-180 (Frignani et al., 2001; Lucchini et al., 2001/2002), measurement ranges in segment 6 were based on five cores for OCDD, OCDF, PCB-180 and $\mathrm{Cu}$ (Frignani et al., 2001, 2004, 2005), and on twenty one cores for $\mathrm{Pb}$ (Frignani et al., 2001; Lucchini et al., 2001/2002).

Except for PCB-180, predicted inter-quartile ranges consistently overlapped with the measured upper sediment contaminant ranges in segment 6 , which indicates that no consistent bias was introduced from the model parameterization and that the parametric uncertainty accounted for much of the model discrepancies (Fig. 2). This finding was also statistically verified by the non-significant $p$-values of the Mann-Whitney $U$ test (the nonparametric equivalent to the $t$ test). Likewise, the model accurately reproduced the spatial variability of the soluble phase $\mathrm{Cu}$ concentrations in the lagoon, and based on the Mann-Whitney test, the predicted values did not differ significantly in segments 3 , $5,7,8$ and 9. However, there were also cases such as that of PCB180 upper sediment concentrations and the dissolved $\mathrm{Pb}$ in the water column (Figs. 2a and e, respectively) that the model consistently overestimated. The model also systematically overestimated most of the upper sediment contaminant levels in segments 7 and 10 indicating that parametric uncertainty was not the sole source of model error. The model bias could be attributed to other sources of error/uncertainty not examined in our analysis such as misspecification of the forcing functions (e.g., contaminant loading estimates especially for PCB 180), error in model structure (e.g., missing processes from the model, possible erroneous parameterization), uncertainty in physico-chemical properties of contaminants or other parameters not considered in this study (Sommerfreund et al., 2009). For example, systematically overestimating sediment concentrations in segments 7 and 10 could be explained by the omission of the episodic flooding events caused by the Bora and Sirocco wind events in the Venice Lagoon. Flooding events associated with these winds enhance sediment resuspension and export to the Adriatic Sea through the lagoon inlets located in segments 3, 7 and 10 (Umgiesser et al., 2004). The overestimation of PCB-180 concentrations throughout the lagoon was likely due to the misspecification of the contaminant loadings. In particular, industrial loadings of PCB-180 are likely attenuated by the sequestration in the sediments of the industrial canals before entering segment 6. Frignani et al. (2004) provided evidence for the latter assertion by reporting maximum PCB concentrations that were 80 to 1583 times higher in the industrial canal sediments than the lagoon sediments. The discrepancy of $\mathrm{Pb}$ in the soluble phase was likely driven by the overestimation of colloidally bound $\mathrm{Pb}$ within the water column by WHAM (Bhavsar et al., 2008).

The magnitude of predicted intra-segment variability (interquartile ranges) was comparable to, or smaller than, all the ranges of measured concentrations with the exception of $\mathrm{Cu}$ in upper sediment. This finding suggests that the uncertainty assigned to the environmental parameters (prior parameter distributions) accounts for a substantial portion of the observed variability in water column and upper sediment concentrations. It should be noted, however, that this comparison was limited since we were able to evaluate only $23 \%$ of model outcomes due to the (un)availability of measured contaminant concentrations.

The ranges of distributions (RoDs) for water and upper sediment concentrations suggested that the uncertainty due to the environmental parameters examined produced model outcomes that varied up to an order of magnitude (Fig. 3). Consistent 
with those reported for similar contaminants (Cao et al., 2004; Matthies et al., 2004), we found that RoDs for the contaminants varied between 0.16 and 1.05 (a value of one indicates an order of magnitude) with a mean of 0.55 . Water column $\mathrm{Cu}$ and $\mathrm{Pb}$ concentrations were characterized by the lowest RoD values amongst the contaminants. Conversely, higher RoDs were found for the organic contaminants. This result is plausible because, unlike metals, the organic contaminants are subject to the variability of the additional removal processes of volatilization and degradation that are mediated by the partitioning of a contaminant between the dissolved and particle-bound phases. In contrast, for the upper sediment concentrations, PCB-180 was found to have the smallest RoD with values varying between 0.16 and 0.41 , while the upper sediment concentrations of $\mathrm{Cu}$ and $\mathrm{Pb}$ had the largest RoDs in the erosive segments 6,7 and 8 . We also found that the effects of the environmental parameter uncertainty were minimal on the upper sediment concentrations in segment 9. These RoD differences highlight the contaminant- and site-specific effects of parametric uncertainty on the model endpoints. Similar results have been reported by others who have attempted to elucidate model uncertainty stemming from the high-dimensional input vectors of multimedia models (e.g., Maddalena et al., 2001; MacLeod et al., 2002; Cao et al., 2004; Citra, 2004; Matthies et al., 2004; Beulke et al., 2006).

\subsection{Modes and driving forces of the model uncertainty}

To identify modes and causal factors underlying the uncertainty of the Venice Lagoon model, we applied PCA in combination with correlation analysis. PCA identified 2 or 3 PCs for the water column concentrations with the exception of PCB-180 for which we extracted 4 PCs (Table 4). The PCs explained $70-88 \%$ of the overall variability in dissolved concentrations. PCA separated the segments into two groups, segments 1-7 and 10 in the northern and central basins of the lagoon, and segments 8 and 9 in the southern lagoon. Based on the correlation analysis, the first PC was strongly associated with the introduction of contaminated sediment from segment 6 (parameter upward 6) driven by erosion. The similar pattern in segments $1-7$ and 10 is possibly associated with the significant mass transport of historical pollution from segment 6 , driven by the clockwise circulation pattern throughout this part of the system. The different behavior of segments 8 and 9 in the southern basin is more closely associated with the loadings to these segments coming from the southern tributaries (Sommerfreund et al., 2009) rather than contaminated sediment from segment 6 . This interpretation is consistent with higher salinities in the central basin (segments 7 and 10) that act as a physical barrier to water movement, thereby limiting mass exchanges between the northern and southern basins (Solidoro et al., 2004b).

b

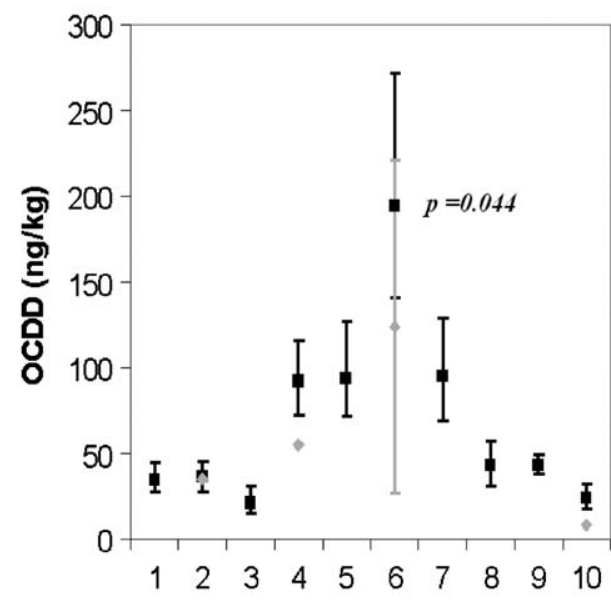

d

C
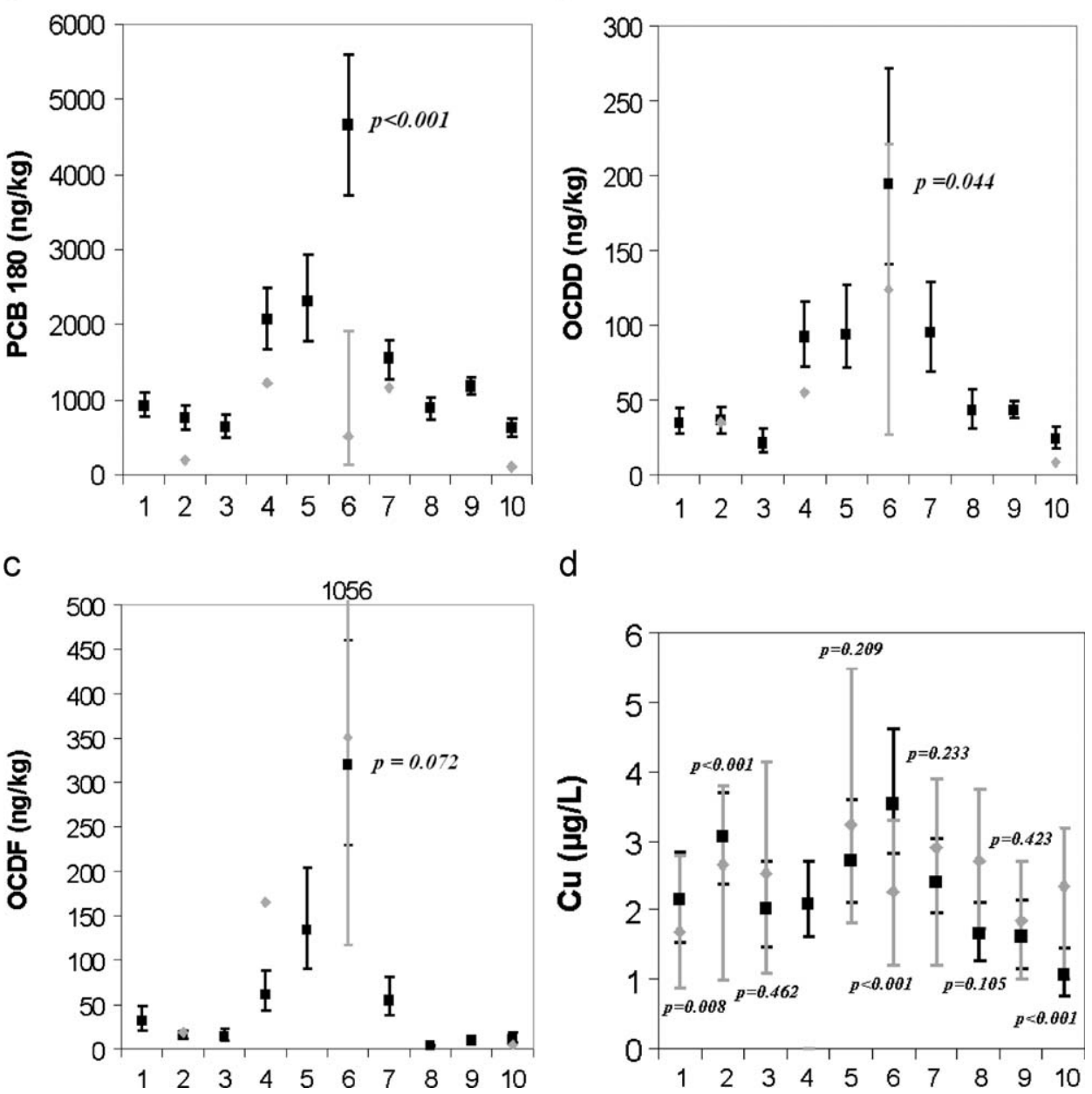

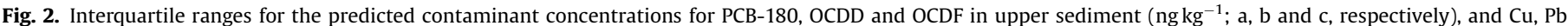

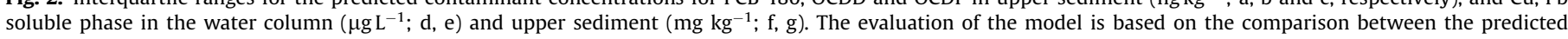

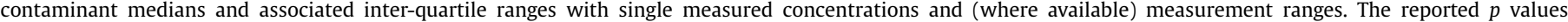
correspond to the Mann-Whitney $U$ test of significance of the discrepancies between observed and modeled concentrations. 
e

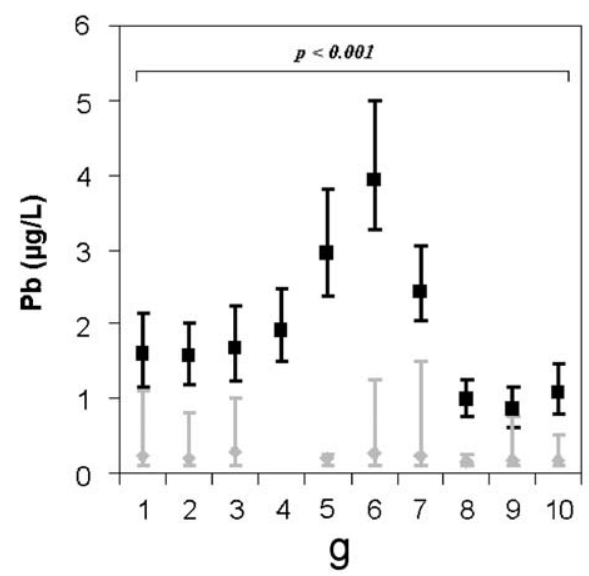

f

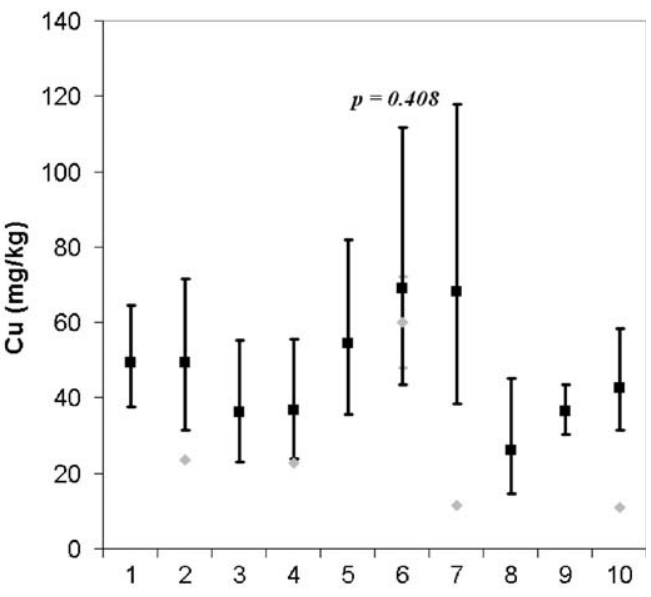

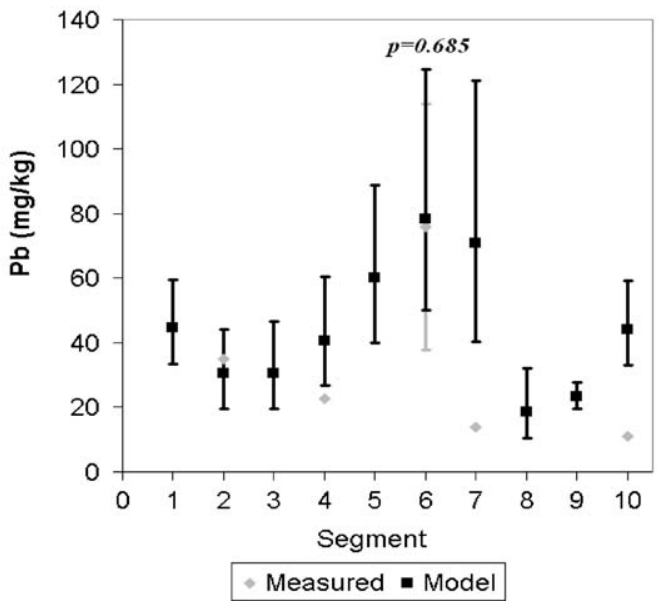

Fig. 2. (Continued)

Variability in the southern segments 8 and 9 was strongly associated with local TSS (TSS 9) which, in turn, mediated water column contaminant concentrations through contaminant partitioning between dissolved and particulate phases. The bimodal contaminant transport pattern of the lagoon (the northern and central basins versus the southern basin) was most evident for $\mathrm{Cu}$ and $\mathrm{Pb}$. For organic contaminants, a third component was extracted that explained up to $14 \%$ of the total variability. The third PC was associated with the variability in the far northern segments 1 and 2 . Organic contaminant transfer from contaminated sediment to the far northern lagoon is, presumably, attenuated by the additional removal pathways of volatilization and degradation. As a result, the influence of uncertainty associated with the erosion parameter in segment 6 was reduced, allowing for the greater influence of variability in local TSS concentrations. The same pattern was more pronounced with PCB-180 concentrations because, unlike other contaminants, the relative contribution of PCB-180 from contaminated sediment was low. Thus, we found a trimodal pattern of segregation for PCB180 ; i.e., northern segments $1-5$ along with segment 6 , southcentral segments 7 and 10 and the far southern segments 8 and 9 .

We identified 2 or 3 PCs for the upper sediment compartment except PCB-180, for which we extracted 5 PCs that explained $55-60 \%$ of the total variation (Table 4 ). The lower percentage of variability explained relative to the water column probably stems from the more locally heterogeneous character of the upper sediment concentrations that are controlled more by in-segment processes and less by inter-segment exchanges. However, the interpretation of the PCs did indicate a general pattern of lagoonwide heterogeneity that separated the far northern segment 2 , the north-central segments 1,3-7 and 10, and the southern segments 8 and 9. Consistent with the water column results, the variability in the central basin segments was strongly associated with contaminated sediment (Upward 6). As with OCDD, OCDF and PCB-180 water column concentrations, upper sediment contaminant variability in the far northern lagoon was associated with local TSS which, in turn, was controlled by flows from local tributaries along with sediment resuspension. Similar mechanistic controls could also explain the patterns in southern segments 8 and 9. The distribution of PCB-180 in upper sediment was spatially heterogeneous and mainly driven by local TSS, while the resulting PCs simply reflected the association among neighboring segments. Finally, upper sediment contaminant variability in the southern lagoon was also related to the sediment burial rate.

\section{Conclusions}

Multimedia modeling of trace contaminants is typified by insufficient data and high-dimensional input parameter spaces leading to considerable uncertainties in model outputs and problems of equifinality, i.e., wide ranges of parameter values subject to complex multivariate relationships that produce 
equivalently accurate predictions. In this study, rather than searching for a single, "most likely" set of values of the 43 environmental model parameters, we employed Monte Carlo sampling to probe structural and parametric uncertainty in our multi-segment, multi-chemical model of the Venice Lagoon.

The results from this probabilistic analysis showed that the modeled contaminant concentrations produced by the 45,000 random parameter sets could vary by up to an order of magnitude (mean of half an order of magnitude). From a risk assessment standpoint, the question arising is to what extent these wide predicted ranges realistically represent the spatial distribution of contaminant concentrations in the Venice Lagoon? Although our study provided evidence that some of the model predictions are supported by the observed data, there are still cases where the lack of information does not allow making definitive statements. Therefore, the spatial uncertainty patterns presented herein can be used to delineate "hot spots", i.e., areas with "high" probability of exceeding threshold contaminant concentrations or, alternatively, areas with "unacceptably high" variance, where future data collection efforts should focus on and determine the actual environmental risks lurking in the system. The delineation of plausible ranges that more objectively represent the spatial

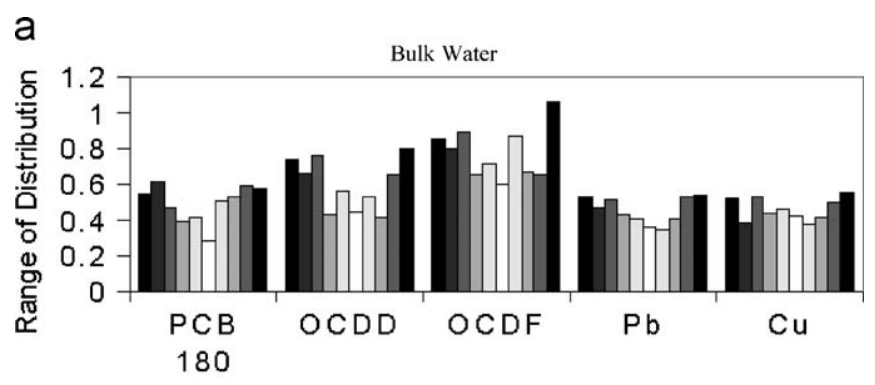

b

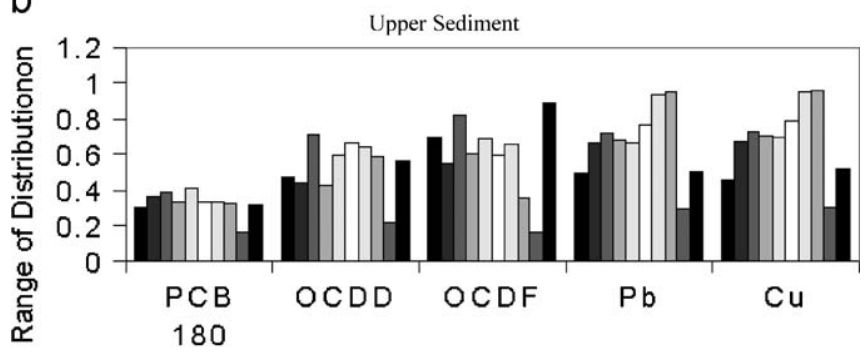

$\square 1 \square 2 \square 3 \square 4 \square 5 \square 6 \square 7 \square 8 \square 9 \square 10$

Fig. 3. Range of distribution (log (90th/10th) percentile) for PCB 180, OCDD, OCDF, $\mathrm{Pb}$ and $\mathrm{Cu}$ for the 10 segments of the Venice Lagoon: (a) bulk water column and (b) upper sediment concentrations. distributions of contaminant concentrations in the Venice Lagoon should also allow the implementation of more advanced uncertainty analysis techniques; Bayesian or (Bayesian-like) methods, such as the Generalized Likelihood Uncertainty Estimation, Sampling/Importance Resampling and Markov Chain Monte Carlo methodologies (Beven and Freer, 2001; Hong et al., 2005; Arhonditsis et al., 2007). Experience from other fields of environmental modeling has highlighted the ability of these methods to offer insights into the degree of information the data contain about model inputs, quantify the dependence structure among parameter estimates and obtain predictions along with uncertainty bounds for modeled output variables.

A correlation analysis between principal components extracted from the Monte Carlo runs and model parameters showed that the spatial distribution of the contaminant concentrations in Venice Lagoon was characterized by 2 modes of variability (i.e., the

Table 4

Segment clustering by contaminant and compartment according to PCA.

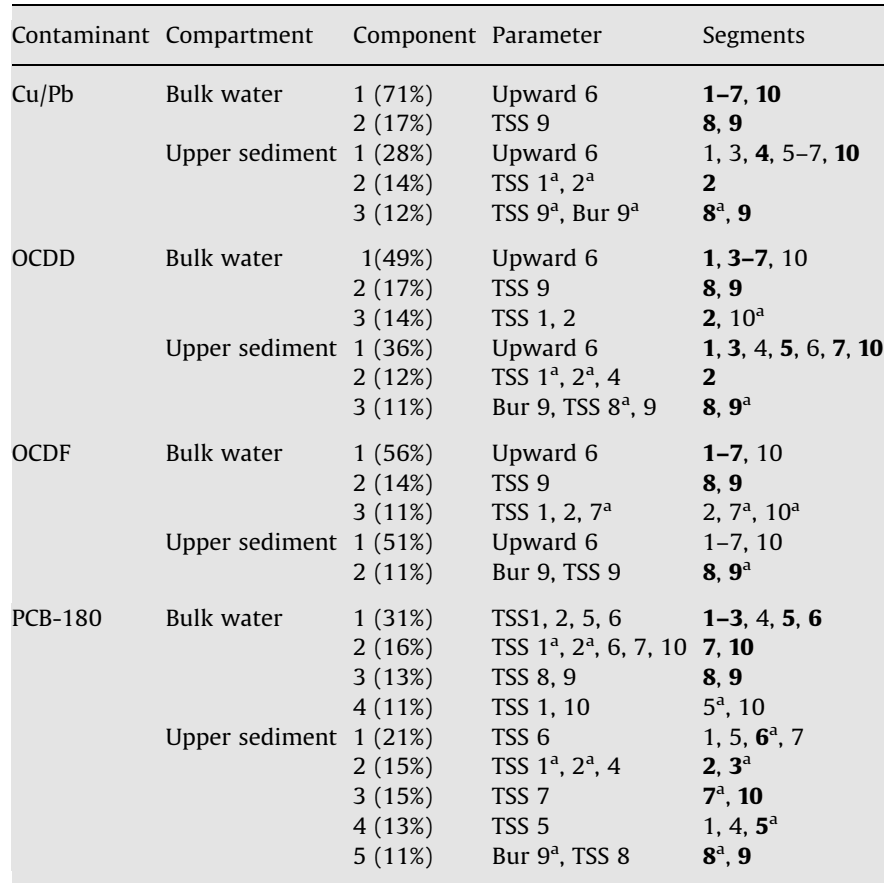

The column "Component" indicates each principal component and the percent of variance explained. The column "Parameter" indicates environmental parameters more high correlated $(>0.3)$ with the respective PC extracted. The column "Segments" shows the most highly loaded $(>0.45)$ segments on the respective PCs, bold indicates significant loading $(>0.65)$.

a Negative relationship.

Table 3

Segment dimensions defined by Solidoro et al. (2004a) and parameter values used for the Venice Lagoon model.

\begin{tabular}{|c|c|c|c|c|c|c|c|c|c|c|}
\hline Segment location ${ }^{a}$ & NBNE & NBNW & NBCW & NBCC & NBCE & CBW & CBE & SBW & $\mathrm{SBC}$ & SBE \\
\hline Segment $\#^{\mathrm{a}}$ & 1 & 2 & 3 & 4 & 5 & 6 & 7 & 8 & 9 & 10 \\
\hline Water depth $(\mathrm{m})^{\mathrm{a}}$ & 1.26 & 0.78 & 3.35 & 0.5 & 1.03 & 1.64 & 2.36 & 0.89 & 0.69 & 1.71 \\
\hline Area $\left(\mathrm{km}^{2}\right)^{\mathrm{a}}$ & 43.5 & 35.3 & 31.3 & 11.5 & 22.2 & 54.3 & 89.4 & 31.7 & 29.5 & 40.6 \\
\hline Organic carbon $(\mathrm{g} / \mathrm{g})$ suspended sediment $\mathrm{t}^{\mathrm{b}, \mathrm{c}}$ & 0.02 & 0.02 & 0.01 & 0.01 & 0.01 & 0.03 & 0.02 & 0.03 & 0.02 & 0.01 \\
\hline Organic carbon $(\mathrm{g} / \mathrm{g})$ upper sediment $\mathrm{t}^{\mathrm{b}, \mathrm{c}}$ & 0.02 & 0.02 & 0.01 & 0.01 & 0.01 & 0.01 & 0.02 & 0.03 & 0.02 & 0.01 \\
\hline Organic carbon $(\mathrm{g} / \mathrm{g})$ lower sediment $\mathrm{t}^{\mathrm{b}, \mathrm{c}}$ & 0.01 & 0.01 & 0.01 & 0.01 & 0.01 & 0.01 & 0.02 & 0.03 & 0.02 & 0.01 \\
\hline Solid volume fraction upper sediment $\mathrm{t}^{\mathrm{b}, \mathrm{c}}$ & 0.52 & 0.48 & 0.64 & 0.53 & 0.58 & 0.60 & 0.61 & 0.61 & 0.61 & 0.66 \\
\hline Solid volume fraction lower sediment $\mathrm{t}^{\mathrm{b}, \mathrm{c}}$ & 0.55 & 0.55 & 0.68 & 0.6 & 0.62 & 0.58 & 0.61 & 0.61 & 0.72 & 0.72 \\
\hline
\end{tabular}

NB — North Basin, CB — Central Basin, SB — South Basin, C—Central, N—Northern, W—West, E-East.

a Solidoro et al. (2004a).

b Secco et al. (2005).

c Amos et al. (2004). 
northern and central parts of the lagoon versus the more isolated southern basin) mainly driven by the local hydrodynamic regime. However, several other contaminant- and site-specific factors induced deviations from this bimodal pattern, such as (i) the interplay among in-place historic pollution in the central lagoon and the sediment burial rates drove the spatial heterogeneity of bulk water and upper sediment contaminant levels and (ii) the TSS concentrations influenced intra-segment variability by controlling contaminant partitioning between the dissolved and particle-bound phases which, in turn, controlled fate by particle movement versus advective flow. The analysis also distinguished between the model errors related to parametric uncertainty and the errors due to model structure/forcing function misspecifications. The latter source of uncertainty resulted in systematic predictive bias (e.g., contaminant overestimation in segments 7 and 10, and all segments for PCB-180), which underscores the importance of elucidating the critical aspects of the system primarily associated with the structural error (uncertain industrial loadings, omission of episodic flooding events) to increase model certainty and reliability.

Skeptical viewpoints usually question the feasibility of rigorously quantifying the uncertainty of contaminant fate and transport model predictions. One usual argument is that the problem of equifinality is more accentuated in contaminant fate and transport modeling, because of the data inadequacy along with the high-dimensional parameter spaces that usually characterize these models. Although we do think that these are legitimate concerns, we also believe that model complexity does not necessarily prohibit an efficient assessment of model uncertainty. In the modeling practice, our experience has been that only a subset of the input parameters is influential on the model outputs (Arhonditsis and Brett, 2005), and therefore an effective calibration should not always be framed in a hyperdimensional context (Kennedy and O'Hagan, 2001). Thus, the collection of information about the key processes that drive contaminant variability in the system and the formulation of welldefined prior distributions for the corresponding parameters is certainly a realistic goal that will significantly assist the implementation of calibration schemes with the ability to accommodate rigorous and complete error analysis; the imperative challenge for the future of environmental modeling (Pappenberger and Beven, 2006).

\section{Acknowledgments}

Funds for this study were provided by the CORILA 2nd Project (2004-2006), Research Line 3.8 "Speciation, distribution, fluxes, bioaccumulation and toxicity of principal contaminants in the Venice Lagoon: experimental and modellistic approach".

\section{References}

Adriano, S., Chiara, F., Antonio, M., 2005. Sedimentation rates and erosion processes in the lagoon of Venice. Environ. Int. 31 (7), 983-992.

Amos, C.L., Beramasco, A., Umgeisser, G., Cappuci, S., Cloutier, D., DeNat, L., Flindt, M., Bonardi, M., Crsitante, S., 2004. The stability of tidal flats in Venice Lagoon - the results of in-situ measurements using two benthic, annular flumes. J. Marine Syst. 51, 211-241.

Arhonditsis, G.B., Qian, S.S., Stow, C.A., Lamon, E.C., Reckhow, K.H., 2007. Eutrophication risk assessment using Bayesian calibration of process-based models: application to a mesotrophic lake. Ecol. Model 208, 215-229.

Arhonditsis, G.B., Adams-VanHarn, B.A., Nielsen, L., Stow, C.A., Reckhow, K.H., 2006. Evaluation of the current state of mechanistic aquatic biogeochemical modelling: citation analysis and future perspectives. Environ. Sci. Technol. 40, 6547-6554.

Arhonditsis, G.B., Brett, M.T., 2005. Eutrophication model for Lake Washington (USA): part I-Model description and sensitivity analysis. Ecol. Model 187, 140-178.
Arhonditsis, G.B., Brett, M.T., 2004. Evaluation of the current state of mechanistic aquatic biogeochemical modelling. Mar. Ecol. Prog. Ser. 271, 13-26.

Bellucci, L.G., Frignani, M., Paolucci, D., Ravanelli, M., 2002. Distribution of heavy metals in sediments of the Venice Lagoon: the role of the industrial area. Sci. Total Environ. 295, 35-49.

Beulke, S., Brown, C.D., Dubus, I.G., Galicia, H., Jarvis, N., Schaefer, D., Trevisan, M., 2006. User subjectivity in Monte Carlo modelling of pesticide exposure. Environ. Toxicol. Chem. 25, 2227-2236.

Beven, K., Freer, J., 2001. Equifinality, data assimilation, and uncertainty estimation in mechanistic modelling of complex environmental systems using the GLUE methodology. J. Hydrol. 249, 11-29.

Bhavsar, S.P., Diamond, M.L., Evans, L.J., Gandhi, N., Nilsen, J., Antunes, P., 2004 Development of a coupled metal speciation-fate model for surface aquatic systems. Environ. Toxicol. Chem. 23, 1376-1385.

Bhavsar, S.P., Gandhi, N., Diamond, M.L., Lock, A.S., Spiers, G., Torre, A.d.l., 2008. Effects of estimates from different geochemical models on metal fate predicted by coupled speciation-fate models. Environ. Toxicol. Chem. 27, 1020-1030.

Cao, H.Y., Tao, S., Xu, F.L., Coveney, R.M., Cao, J., Li, B.G., Liu, W.X., Wang, X.J., Hu, J.Y. Shen, W.R., Qin, B.P., Sun, R., 2004. Multimedia fate model for hexachlorocyclohexane in Tianjin, China. Environ. Sci. Technol. 38, 2126-2132.

Carrer, S., Leardi, R., 2006. Characterizing the pollution produced by an industrial area-chemometric methods applied to the Lagoon of Venice. Sci. Total Environ. 370, 99-116.

Citra, M.J., 2004. Incorporating Monte Carlo analysis into multimedia environmental fate models. Environ. Toxicol. Chem. 23, 1629-1633.

Collavini, F., Bettiol, C., Zaggia, L., Zonta, R., 2005. Pollutant loads from the drainage basin to the Venice Lagoon (Italy). Environ. Int. 31, 939-947.

Costanza, R., Sklar, F.H., 1985. Articulation, accuracy and effectiveness of mathematical-models - a review of fresh-water wetland applications. Ecol. Model 27, 45-68.

Cowan, C.E., MacKay, D., Feijtel, T.C.J., van de Meent, D., di Guardo, A., Davies, J., Mackay, D., 1994. The Multi-Media Fate Model: A Vital Tool for Predicting the Fate of Chemicals. SETAC Press, Pensacola, Florida.

Degetto, S., Cantaluppi, C., 2004. Radiochemical methodology for the determination of the mass balance of suspended particulate materials exchanged at the inlets of the Venice Lagoon. J. Marine Syst. 51, 77-94.

Diamond, M.L., Mackay, D., Welbourn, P.M., 1992. Models of multimedia partitioning of multispecies chemicals - the fugacity equivalence approach Chemosphere 25, 1907-1921.

Diamond, M.L., Mackay, D., Poulton, D.J., Stride, F.A., 1994. Development of a mass balance model of the fate of 17 chemicals in the Bay of Quinte. J. Great Lakes Res. 20, 643-666.

Diamond, M.L., 1995. Application of a mass-balance model to assess in-place arsenic pollution. Environ. Sci. Technol. 29, 29-42.

Diamond, M.L., Bhavsar, S.P., Helm, P.A., Stern, G.A., Alaee, M., 2005. Fate of organochlorine contaminants in arctic and subarctic lakes estimated by mass balance modelling. Sci. Total Environ. 342, 245-259.

Frignani, M., Bellucci, L.G., Carraro, C., Raccanelli, S., 2001. Polychlorinated biphenyls in sediments of the Venice Lagoon. Chemosphere 43, 567-575.

Frignani, M., Bellucci, L.G., Carraro, C., Favotto, M., 2004. Accumulation of polychlorinated biphenyls in sediments of the Venice Lagoon and the industrial area of Porto Marghera. Chemosphere 54, 1563-1572.

Frignani, M., Bellucci, L.G., Favotto, M., Albertazzi, S., 2005. Pollution historical trends as recorded by sediments at selected sites of the Venice Lagoon. Environ. Int. 31, 1011-1022.

Gambaro, A., Manodori, L., Moret, I., Capodaglio, G., Cescon, P., 2004. Determination of polychlorobiphenyls and polycyclic aromatic hydrocarbons in the atmospheric aerosol of the Venice Lagoon. Anal. Bioanal. Chem. 378, 1806-1814.

Guerzoni, S., Rossini, P., Molinaroli, E., Rampazzo, G., Raccanelli, S., 2004 Measurement of atmospheric deposition of polychlorinated dibenzo-p-dioxins and dibenzofurans in the Lagoon of Venice, Italy. Chemosphere 54, 1309-1317.

Hong, B.G., Strawderman, R.L., Swaney, D.P., Weinstein, D.A., 2005. Bayesian estimation of input parameters of a nitrogen cycle model applied to a forested reference watershed, Hubbard Brook Watershed Six. Water Resour. Res. 41, W03007.

Jassby, A.D., 1999. Uncovering mechanisms of interannual variability from short ecological time series. In: Scow, K.M., Fogg, G.E., Hinton, D.E., Johnson, M.L. (Eds.), Integrated Assessment of Ecosystem Health. CRC Press, Boca Raton, FL, pp. 285-306.

Kennedy, C.M., O'Hagan, A., 2001. Bayesian calibration of computer models. J. R. Stat. Soc. B 63, 425-464

Kuhne, R., Breitkopf, C., Schuurmann, G., 1997. Error propagation in fugacity levelIII models in the case of uncertain physicochemical compound properties. Environ. Toxicol. Chem. 16, 2067-2069.

Legendre, P., Legendre, L., 1998. Numerical Ecology, second English ed. Elsevier Science, Amsterdam.

Liu, C., Bennett, D.H., Kastenberg, W.E., McKone, T.E., Browne, D., 1999. A multimedia, multiple pathway exposure assessment of atrazine: fate, transport and uncertainty analysis. Reliab. Eng. Syst. Saf. 63, 169-184.

Lucchini, F., Frignani, M., Sammartino, I., Dinelli, E., Bellucci, L.G., 2001/2002. Composition of Venice Lagoon sediments: distribution, sources, settings and recent evolution. GeoActa $1,1-14$.

Mackay, D., 2001. Multimedia Environmental Models: The Fugacity Approach. Lewis Publishers, Boca Raton, FL. 
MacLeod, M., Fraser, A.J., Mackay, D., 2002. Evaluating and expressing the propagation of uncertainty in chemical fate and bioaccumulation models. Environ. Toxicol. Chem. 21, 700-709.

Maddalena, R.L., McKone, T.E., Hsieh, D.P.H., Geng, S., 2001. Influential input classification in probabilistic multimedia models. Stoch. Environ. Res. Risk Assess. 15, 1-17.

Manodori, L., Gambaro, A., Moret, I., Capodaglio, G., Cairns, W.R.L., Cescon, P., 2006 Seasonal evolution of gas-phase PCB concentrations in the Venice Lagoon area. Chemosphere 62, 449-458.

Matthies, M., Berding, V., Beyer, A., 2004. Probabilistic uncertainty analysis of the European Union System for the evaluation of substances multimedia regional distribution model. Environ. Toxicol. Chem. 23, 2494-2502.

MAV-SAMA, 2004. Qualità delle acque e degli scarichi idrici dell'area di Porto Marghera. Dati relativi al 2001-2002. Sezione Antinquinamento del Magistrato alle Acque, Venezia.

McKone, T.E., Ryan, P.B., 1989. Human exposures to chemicals through food-chainsan uncertainty analysis. Environ. Sci. Technol. 23, 1154-1163.

McKone, T.E., 1994. Uncertainty and variability in human exposures to soil contaminants through home-grown food-a Monte-Carlo assessment. Risk Anal. 14, 449-463.

McKone, T.E., 1996. Alternative modelling approaches for contaminant fate in soils: uncertainty, variability, and reliability. Reliab. Eng. Syst. Saf. 54, 165-181.

Omlin, M., Reichert, P., 1999. A comparison of techniques for the estimation of model prediction uncertainty. Ecol. Model 115, 45-59.

Pappenberger, F., Beven, K.J., 2006. Ignorance is bliss: or seven reasons not to use uncertainty analysis. Water Resour. Res. 42, W05302.

Pranovi, F., Da Ponte, F., Raicevich, S., Giovanardi, O., 2004. A multidisciplinary study of the immediate effects of mechanical clam harvesting in the Venice Lagoon. ICES J. Mar. Sci. 61, 43-52.

Reckhow, K.H., 1994. A decision-analytic framework for environmental-analysis and simulation modelling. Environ. Toxicol. Chem. 13, 1901-1906.
Secco, T., Pellizzato, F., Sfriso, A., Pavoni, B., 2005. The changing state of contamination in the Lagoon of Venice. Part 1: organic pollutants. Chemosphere 58, 279-290.

Sfriso, A., Facca, C.F., Marcomini, A., 2005a. Sedimentation rates and erosion processes in the lagoon of Venice. Environ. Int. 31, 983-992.

Sfriso, A., Facca, C., Ceoldo, S., Pessa, G., 2005b. Sedimentation Rates, Erosive Processes, Grain-Size and Sediment Density Changes in the Lagoon of Venice, Scientific Research and Safeguarding of Venice, 2003 Results. CORILA.

Sinkkonen, S., Paasivirta, J., 2000. Degradation half-life times of PCDDs, PCDFs and PCBs for environmental fate modelling. Chemosphere 40, 943-949.

Solidoro, C., Pastres, R., Cossarini, G., Ciavatta, S., 2004a. Seasonal and spatial variability of water quality parameters in the lagoon of Venice. J. Mar. Syst. 51, 7-18.

Solidoro, C., Canu, D.M., Cucco, A., Umgiesser, G., 2004b. A partition of the Venice Lagoon based on physical properties and analysis of general circulation. J. Mar. Syst. $51,147-160$.

Sommerfreund, J., Diamond, M.L., Frignani, M., Capodaglio, G., Gerino, M., Bellucci, L.G., Giuliani, S. Contaminant fate and transport in the Venice Lagoon: results from a multi-segment multimedia model. Ecotoxicology and Environmental safety, submitted for publication.

Spear, R.C., 1997. Large simulation models: calibration, uniqueness and goodness of fit. Environ. Modell. Software 12, 219-228.

Steinberg, L.J., Reckhow, K.H., Wolpert, R.L., 1997. Characterization of parameters in mechanistic models: a case study of a PCB fate and transport model. Ecol. Model 97, 35-46.

Umgiesser, G., Canu, D.M., Cucco, A., Solidoro, C., 2004. A finite element model for the Venice Lagoon. Development, set up, calibration and validation. J. Mar. Syst. 51, 123-145.

Wania, F., Mackay, D., 1999. The evolution of mass balance models of persistent organic pollutant fate in the environment. Environ. Pollut. 100, 223-240.

Webster, E., Mackay, D., Di Guardo, A., Kane, D., Woodfine, D., 2004. Regional differences in chemical fate model outcome. Chemosphere 55, 1361-1376. 